\title{
On the Prospects of the Development of Non-public Ownership Economy under the Background of Big Data
}

\author{
Manli Jia ${ }^{1, *}$ \\ ${ }^{1}$ Inner Mongolia Normal University,Inner Mongolia Municipality,010010
}

\begin{abstract}
This article analyzes the interaction between big data and the non-public economy. The author studied the problems faced in the deep fusion process. The research content of this paper includes data source activation, data cleanup, hidden dangers of data content, shortage of talents for analysis, and development of integrated platforms. The author analyzes how to establish a comprehensive development platform, improve the in-depth integration model, enhance the awareness of data application, do a good job in personnel training, improve the safety management mechanism, optimize the resource development environment, and do a good job in market supervision and management. The purpose of this article is to speed up the integration of big data and the non-public economy, and promote the development of enterprise economy.
\end{abstract}

\section{Introduction}

Judging from the current development situation, the world has entered the era of big data. As shown in Figure 1 , the world's big data reserves are in an explosive state. With the rapid development of Internet technology, China's big data industry has also developed rapidly. The China Academy of Information and Communications Technology combined with the survey and calculation of big data-related companies and found that the scale of China's big data industry has grown steadily. From 2016 to 2019, in just four years, the size of China's big data industry market has grown from 284.08 billion yuan to 538.62 billion yuan, and the growth rate has remained above $20 \%$ for four consecutive years. As shown in Figure 2, it is the forecast of China's big data industry market growth from 2019 to 2023.

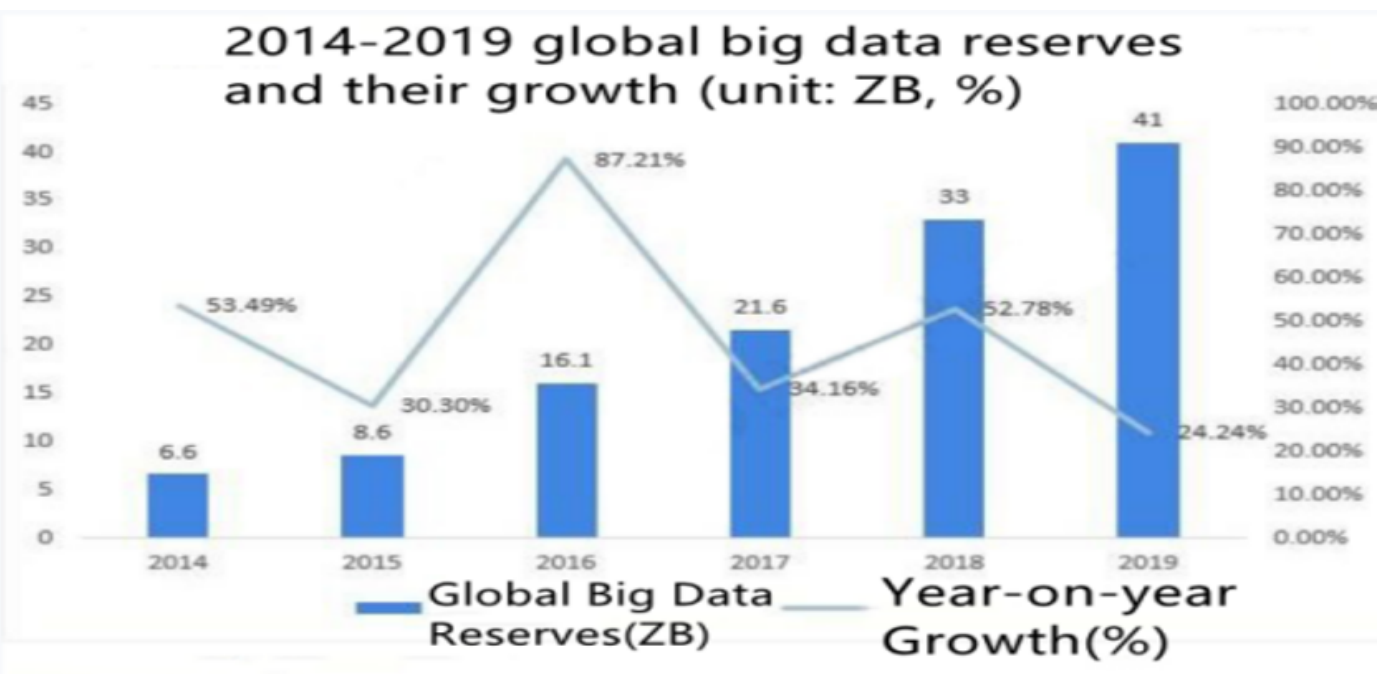

Fig. 1. 2014-2019 Global Big Data Reserves and Their Growth (unit: ZB, \%) 


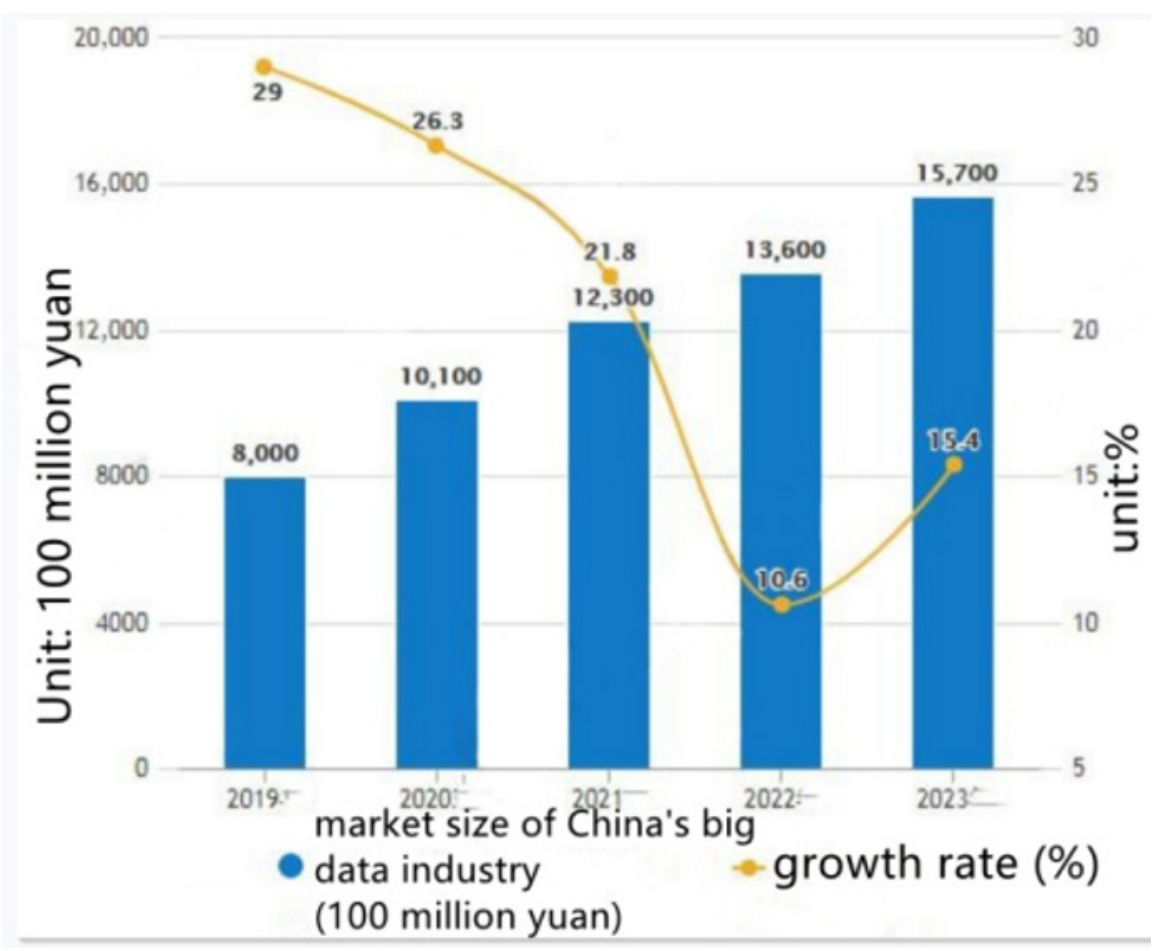

Fig. 2. 2019-2023 China's Big Data Industry Market Size Statistics and Growth Forecast

At present, China as a whole is in an important stage of economic system optimization, transformation and upgrading. The non-public ownership economy has also been effectively developed in this process. Based on the advantages of big data technology application, fully integrating it with the development of the non-public economy can not only speed up the transformation of enterprises, but also enhance the competitiveness of enterprises in the market and meet the requirements of healthy development of enterprises. ${ }^{[1]}$

\section{The Mutual Influence of Big Data and the Non-public Economy}

The big data industry has become an emerging economic form. Data openness and strong application requirements have spawned a large number of "double innovation" SMEs, and these non-public enterprises have become the main body of mining the value of big data. Public-owned enterprises and non-public public-owned enterprises are quietly merging. A new type of non-public economic paradigm that takes data as the center and emphasizes statistics, quantification and data relevance instead of concept deduction, conceptual reasoning, and logical connection has emerged, as shown in Figure 3.

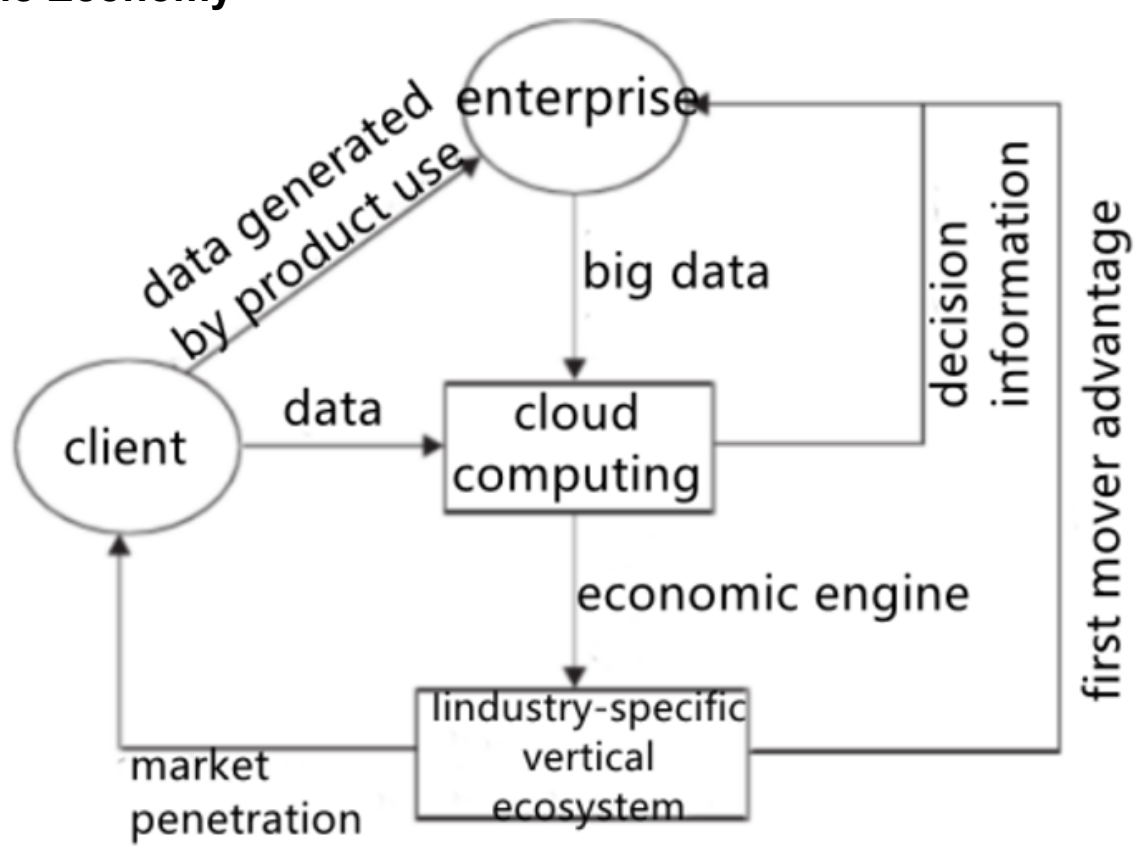

Fig. 3. Relying on Big Data Technology Non-public Economic Development Model 


\subsection{Big Data Affects the Non-public Economy}

\subsubsection{Improve Decision-making Predictability}

Under the vigorous guidance and promotion of the Chinese government, big data is being widely used in transportation, logistics, advertising, telecommunications, medical care, entertainment, agriculture and other fields, and related industries are booming. Making decisions based on in-depth economic situation and industrial development data can not only make a rough forecast of its future development trend, but also realize the optimal allocation of limited resources, and better lead the direction of transformation and upgrading of non-public enterprises. In addition, this can also promote mutual understanding between the real economy and the virtual economy, the non-public economy and the public economy, as well as the individual economy, the private economy and the foreign-funded economy in the non-public economy. This can also reduce repetitive production and achieve coordinated and balanced development. ${ }^{[2]}$

\subsubsection{Improve Model Accuracy}

The society can generate massive amounts of data every day, and cloud computing technology and information technology for big data processing can streamline $20 \%-30 \%$ of value data from more than $95 \%$ of the massive data. These value data can play a good guiding role in the development of the enterprise. At the same time, these data can also capture personal consumption patterns, consumption habits, consumption frequency, consumption content and other information from the Internet, and use this to improve the pertinence and effectiveness of the push information. For example, currently more than $80 \%$ of enterprises have launched services such as "private customization" and "personalized push". In the context of increasingly prominent personalized needs, such content will also help companies expand the number of audiences. It helps to speed up the development of non-public ownership. ${ }^{[3]}$

\subsubsection{Improve the Scientific Nature of the Manager} Team

Based on the background of big data development, the number of managers serving the non-public economy is also increasing. At the same time, poorly qualified managers also give users a poor service experience. This will affect the conventional development of the non-public ownership economy to a certain extent. Therefore, companies need to make full use of big data to provide information to compare the comprehensive strength of different managers' management teams in a quantitative analysis method. Reference indicators include professional experience, social impact, and profitability. This has also helped the manager market to establish a "elimination mechanism", so that some unqualified managers are gradually eliminated by the market, leaving behind a team of managers with a high level of comprehensiveness. This has also provided necessary talent support for the stable development of the non-public economic market. ${ }^{[4]}$

\subsubsection{Improve the Convenience of Financing Required}

Over the years, Chinese SMEs have generally faced difficulties in financing and expensive financing. The integration of big data and non-public economic development can break through the shackles of traditional credit mechanisms in time and space, effectively reduce information asymmetry, eliminate the information gap between borrowers and lenders, and realize the reengineering and transformation of credit business processes. This can also effectively control risks while improving economic efficiency, allowing both borrowers and lenders to achieve mutual benefit and win-win results. This is of great significance to the financing and reproduction of non-public enterprises. Table 1 shows the efficiency comparison of the main financing models of non-public enterprises. ${ }^{[5]}$

Table 1. Comparison of Different Financing Methods

\begin{tabular}{|c|c|c|c|}
\hline Financing & Mortgage & Mortgage & Online Microfinance \\
\hline Credit Conditions & Fixed Assets & Orders, Warehouses, etc. & Credit Data \\
\hline Work Efficiency & Lower & Middle & Higher \\
\hline
\end{tabular}

\subsection{Non-public Ownership of the Economy Affects Big Data}

\subsubsection{Provide A Habitat for Big Data}

Based on the economic data of 2016-2020 statistics, it can be understood that the economic value created by the non-public sector of the economy is currently on the rise, and its current share of GDP has exceeded $60 \%$. Meanwhile, the non-public ownership economy also provides more than $50 \%$ of fiscal taxes and more than $75 \%$ of employment opportunities. It has become an important source of power in the development of Chinese society. Compared with the public-owned economy, the non-public-owned economy has complex business content and various consumer behaviors, and it is the main producer of big data. Moreover, the development of the non-public ownership economy also needs the support of massive amounts of data. This is also an important guarantee to ensure the competitiveness of enterprises. ${ }^{[6]}$ 


\subsubsection{Big Data Incubator}

At present, the non-public ownership economy has become the backbone of social development in the process of development. Moreover, big data has penetrated into various industries for in-depth integration and application during the development of the non-public economy. As shown in Figure 4, the types of big data application enterprises have covered the development of non-public enterprises in the country's main economic sectors with high-tech technology as the main force. The vigorous development of the non-public economy can also provide the necessary development capital for big data, and then use big data to create more application value to feed back the further development of the non-public economy. At present, many technologies have been introduced to assist big data processing. In the meantime, the use of reasonable development tools can also assist the development and application of value data in big data to meet the basic needs of stable economic development of enterprises.

\section{Distribution of Big Data Application Companies in China}

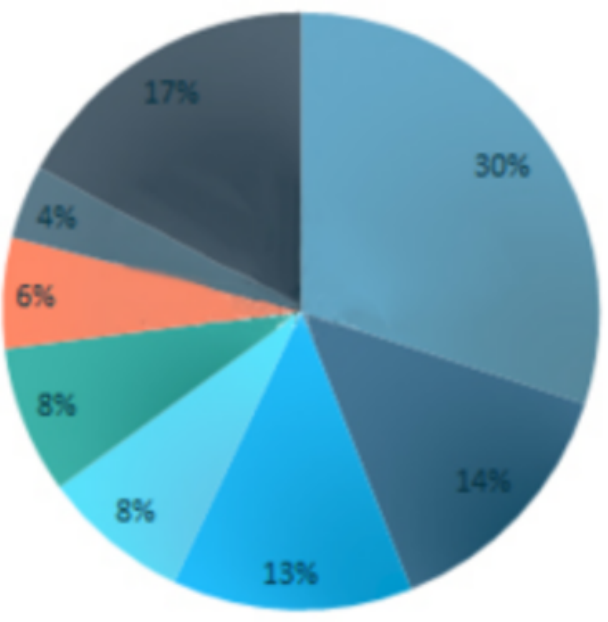

medical health

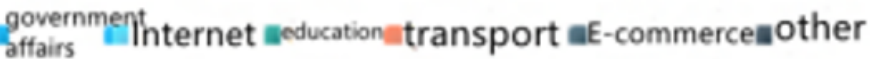

Fig. 4.Distribution of Big Data Application Companies in China

\subsubsection{The Development Highland of Big Data}

The development time of big data is relatively short, but it has been expanded and integrated in many fields to create application value for enterprise development. Moreover, big data is not a new profession. It can be smoothly integrated with existing industries in applications. In the meantime, it can also provide a reference for the optimization of operating models and speed up the optimization of existing models. Meanwhile, in the market environment, there will be industry competition and industry alliances in the non-public sector of the economy. During this period, reliable data interaction is more necessary. It also creates a good application environment for the rapid development of big data itself to meet specific application needs.

\section{Problems Faced in the Process of Deep Integration}

\subsection{Data Source Activation Problem}

Based on past data collation experience, it can be understood that more than $80 \%$ of non-public economic data are in the hands of the government. However, more than $50 \%$ of this part of the data is in the idle state and cannot be used effectively. This has also hindered the development of the non-public sector of the economy. The remaining $20 \%$ of the data is circulated on the market, and the source is basically Internet companies, government open information, financial companies, etc. There are many types of data needed and mastered by complex enterprises, but these data are rarely rented out. According to the survey data in 2020 , less than $10 \%$ of compound enterprises provide information leasing services, and there is still a large gap in the supply and demand of information in the market. 


\subsection{Organize Data Cleaning Issues}

In the process of big data application, it is also faced with the problem of greater difficulty in cleaning up. Big data has the characteristics of a wide variety of information and a large amount of foundation. Simultaneously, there are many sources of data and information, and people cannot quickly judge the accuracy and authenticity of the information. Although cloud computing technology and information technology are available to assist in the advancement of work, the overall processing is more difficult, and more effective processing methods are needed to speed up information screening. Besides, the content of the data formats currently circulating in the market is relatively diverse. Such as pictures, videos, compressed packages, etc. are all common big data formats. These data are also difficult to integrate and process. ${ }^{[7]}$

\subsection{Data Content Hidden Problems}

Under the background of the big data era, the difficulty of obtaining information is relatively low, and there are more ways to obtain information, but at the same time, there are corresponding hidden dangers. According to statistics from 2016 to 2020, cases of personal or corporate privacy data leakage are increasing at an annual rate of $10 \%-12 \%$, which will also have serious negative effects on individuals or companies. From the perspective of function types, the number of games with high-risk vulnerabilities in personal privacy data leakage accounts for $18.78 \%$ of the country's total, ranking first. The number of applications with high-risk vulnerabilities in daily life applications accounted for $14.01 \%$ of the country's total, ranking second. The number of applications with high-risk vulnerabilities in office learning applications accounted for $10.46 \%$ of the country's total, ranking third. Figure 5 shows the ranking of applications with high-risk vulnerabilities in the personal privacy leakage function category.

For example, Tencent and Alibaba are subject to millions of malicious attacks every day. If the core data is stolen, it will also bring a very big social security risk. At present, big data protection technology is still in the perfect stage. This also affects data defense to a certain extent, which is also the content that needs to be focused on in subsequent development.

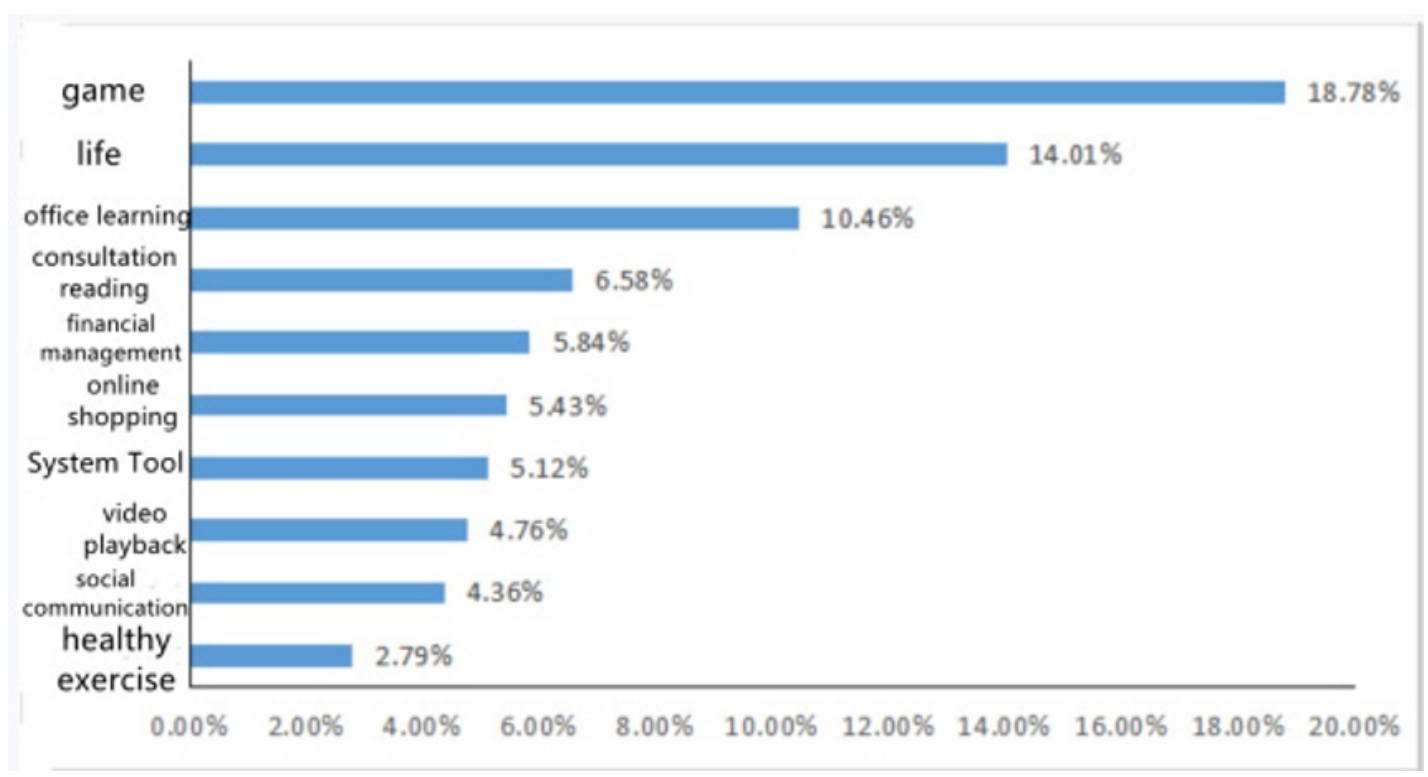

Fig. 5.The Proportion of Applications with High-risk Vulnerabilities in Functional Types

\subsection{Analyze the Shortage of Talents}

In the process of big data management, it is necessary to match professional talents to assist the work. However, according to the employment rate of related industries from 2016 to 2020 , the ratio of supply to demand is less than $70 \%$, and $30 \%$ of job vacancies are still left. The integration of big data into the non-public sector of the economy is inseparable from the support of big data talents, and the talent pool for economic analysis is even smaller. This will also form a major obstacle to the development of the enterprise, which also limits the smooth development of in-depth integration work.

\subsection{Integrated Platform Development Issues}

Except to the application problems mentioned above, there are also problems in the development of integrated platforms in the development of big data technology. From the current big data processing situation, the frequently used platforms include Map Rede, Hadoop, etc. However, the number of platforms serving the integration of the non-public economy and big data is relatively small. In particular, there are fewer platforms in data mining, which also reduces the application value of big data to a certain extent. Moreover, this also delays the speed of integration between the two and limits the further development of the non-public economy. ${ }^{[8]}$ 


\section{Deep Integration of Big Data and Non-public Economic Development}

\subsection{Establish A Comprehensive Development Platform}

The establishment of a comprehensive development platform is conducive to enhancing the application value of big data and meeting the development needs of the non-public economy. In the specific construction process, companies need to make full use of the advantages of Internet technology to establish an online communication service platform. Linking companies and functional departments can provide a good channel for interaction. On the platform, basic corporate information such as business status, development needs, and development bottlenecks will be gathered. Compared with the previous data collection process, this platform can increase the amount of data storage by $50 \%-70 \%$. In addition, this platform builds a hub with functional departments. This also facilitates the interactive communication of information. This is also conducive to the rapid sharing of some data information, so that the previously idle data can better play its application value.

\subsection{Perfect the Deep Integration Model}

By improving the deep integration model, the integration speed between big data and the non-public economy can be accelerated, thereby enhancing the application value of big data itself. In the specific practice process, companies need to sort and sort updated data to eliminate non-compliant, duplicate, and erroneous data. Simultaneously, companies will also fully process data resources, filter out the required value data, and improve the convenience of the data application process. In the process of model application, the non-public economic statistics method will also be optimized. Furthermore, companies can scientifically organize market demand information and feedback data, make reasonable predictions in time, and effectively monitor the entire process. Thereby improving the effectiveness of data analysis results and meeting the related needs of integrated development.

\subsection{Raise Awareness of Data Application}

Improving the awareness of data application is not only conducive to the rapid progress of the two fusion process, but also can improve the efficiency of the data itself. Since 2017, according to relevant statistical data, it can be understood that the cost of big data needs to be kept at about 3 million yuan. Only in this way can the basic needs of development be met. However, according to statistical data, at least $50 \%$ of enterprises cannot meet this requirement. In most cases, the investment of enterprises is less than 1 million yuan. This is also directly related to corporate consciousness. In practical applications, companies need to correctly recognize the value of big data. At the same time, companies need to take reasonable measures to bring out the value of technology smoothly. This can meet the needs of enterprise development and increase the speed of integration between the two.

\subsection{Do A Good Job in Talent Training}

Good talent training can lay the foundation for the smooth development of activities and promote the healthy development of the enterprise economy. From a practical point of view, it can strengthen the cooperative relationship with universities in the specific application process, and oriented to cultivate constructive talents that meet the needs of social development. This can increase the reserve of such talents in society. Meanwhile, non-public enterprises also need to do a good job in external recruitment and internal training. The former is to increase the company's talent pool through online recruitment and local recruitment. The latter is to organize corresponding training activities on a regular basis to help improve the comprehensive ability of personnel. This can enhance the comprehensive strength of the enterprise management team and lay the foundation for the advancement of in-depth integration work.

\subsection{Improve Safety Management Mechanism}

By improving the security management mechanism, information security can be improved and the risk of information leakage can be reduced. In the specific development process, companies need to fully integrate security technology and management platforms to do a good job of data detection during work. In this way, the dangerous data can be eliminated in time, thereby improving the reliability and practicability of the data analysis results. In the meantime, companies also need to establish a reliable guarantee system based on actual needs and conduct standardized processing of application content. Moreover, companies can accurately identify common dangerous codes, update the security assurance system from time to time, and refine the relevant content in the security system. This is conducive to improving the reliability and use value of the content, and creating a good business development environment.

\subsection{Optimize the Resource Development Environment}

By optimizing the resource development environment, the utilization efficiency of data resources can be improved, and the integration speed between big data and the non-public economy can be accelerated. In the actual process, companies need to integrate data resources. Companies can use the platform to complete big data classification and sorting, with reasonable data keywords, to facilitate the convenience of the subsequent data information extraction process. Besides, companies will also rely on the Internet to establish resource management mechanisms. Enterprises allocate resources reasonably according to application needs in different 
situations. Otherwise, companies need to do a good job in the collection of data information feedback content. Enterprises should optimize the management system based on the collected results to improve the reliability of the analysis results.

\subsection{Do A Good Job in Market Supervision and Management}

By doing a good job in market supervision and management, bad behaviors in the market can be discovered in time, so as to optimize the content of market development. Reasonably use Internet technology to sort out the dynamic information of market development. In addition, companies will also use the management system for data screening to remove unreasonable data in a timely manner, thereby improving the orderliness of the market development process .

\section{Conclusion}

In summary, the establishment of a comprehensive development platform is conducive to enhancing the application value of big data. Improving the deep integration model can speed up the integration between big data and the non-public economy. Enhancing the awareness of data application is conducive to the rapid progress of the fusion process of the two. Doing a good job of talent training can lay the foundation for the smooth development of activities. Improving the security management mechanism can improve information security. Optimizing the resource development environment can improve the utilization efficiency of data resources. Good market supervision and management can detect bad behaviors in the market in time. Taking reasonable measures to accelerate the integrated development of big data and the non-public economy is of positive significance for optimizing the social and economic development system.

\section{References}

1. Junhui Shi. Thoughts on the high-quality development of Loudi's private economy[J]. Cooperative Economy and Technology, 2021(07): 24-25.

2. Zhang Tian. On the development path of Shaanxi's non-public economy under the supply-side reform[J]. Journal of Hubei University of Economics (Humanities and Social Sciences Edition), 2021, 18(04): 50-53.

3. Xianglin $\mathrm{Xu}$. Leading the high-quality development of the non-public economy with party building[J]. National Governance, 2021(11): 45-46.

4. Lingling Tian, Chen Lian, Luo Jing, Kaiyuan Sun, Zhou Lin, Wang Zi, Guolei Chen. The spatiotemporal pattern and driving mechanism of the high-quality development of China's private economy [J]. Economic Geography, 2021, 41(01): 131- 139.

5. Xiaojun Zhang. An analysis of business countermeasures for the development of non-public ownership economy in counties in Northwest China_-Taking Maiji District, Tianshui City, Gansu Province as an example [J]. Economic Research Guide, 2021(02): 45-47.

6. Zhengfeng Qiu. Analysis of the relationship between "elimination of private ownership" and the development of non-public ownership economy [J]. Journal of Jiaozuo University, 2020, 34(04): 9-12.

7. Fusheng Xie, Wang Song. Promote the common development of public and non-public economies in the collaborative competition $[\mathrm{J}]$. Teaching and Research, 2020(12): 26-38.

8. Li Ting, Wang Jian, Cheng Chong. Research on the Combination of Qinghai Province's Promotion of Non-public Ownership Economy Development and Precision Poverty Alleviation[J]. Guangxi Quality Supervision Guide, 2020(11): 48-49. 